\title{
Protective Effect of Mulberry Leaf and Yacon Extract Induced Hyperlipidemia in Obese Rats
}

\author{
Yong Lim ${ }^{1, *}$, Ji Hye Oh${ }^{2, * *}$, Un Kyu Park ${ }^{2, * *}$, Man Kyu Huh ${ }^{3, *}$ and Seock-Yeon Hwang, ${ }^{2, \dagger, *}$ \\ ${ }^{I}$ Department of Clinical Laboratory Science, Dong-eui University, Busan 47340, Korea \\ ${ }^{2}$ Department of Biomedical Laboratory Science, Daejeon University, Daejeon 34520, Korea \\ ${ }^{3}$ Food Engineering and Technology Major, Dong-eui University, Busan 47340, Korea
}

There has been a lot of interest in medicinal effects for hyperlipidemia from the natural product since the therapy of atherosclerosis has emerged as social concern. Rats were acclimated to the feeding environment for one week and induced to obesity with high fat diet during 4 weeks until their body weight were more than $30 \%$ of normal range. To evaluate the effect of hyperlipidemia of mulberry leaf of Morus alba and yacon tuber of Smallanthus sonchifolia extracts (MLYT), $1 \%, 3 \%, 5 \%$ of MLYT were treated to Sprague-Dawley rats. Aspartate transaminase (AST) was significantly increased $26.2 \%$ in high fat diet group (G2) compared to normal diet group (G1) $(P<0.05)$. But AST were significantly decreased in high fat diet with $0.5 \%$ hydroxycitric acid diet group (G3) and all the MLYT treated groups compared to G2. Total cholesterol, low-density lipoprotein (LDL), triglycerides and phospholipids were observed significant improvements in the MLYT-treated groups $(P<0.05)$. These improvements in liver and feces were further supported by the lipid content. MLYT remarkably suppressed the level of lipid peroxidation caused by high-fat diet in rats. The level of 3-hydroxy3-methyl-glutaryl-coenzyme A (HMG-CoA) reductase activity. As a result, the proper combination of mulberry leaves and yacon tuber extract will have a synergistic effect on hyperlipidemia. These results indicate that MLYT could be a candidate for the improvement of hyperlipidemia.

Key Words: 3-hydroxy-3-methyl-glutaryl-coenzyme A (HMG-CoA), Hyperlipidemia, Morus alba, Smallanthus sonchifolia, Total cholesterol

\section{INTRODUCTION}

Hyperlipidemias are divided into primary and secondary subtypes. Primary hyperlipidemia is usually due to genetic causes (such as a mutation in a receptor protein), while secondary hyperlipidemia arises due to other underlying causes such as diabetes. In 2015-2016, 12.4\% of adults in America had high total cholesterol (Carroll et al., 2017).
Statin drugs in clinical therapeutics have been mostly used in hyperlipidemia treatment (Davis et al., 2016). The mechanism of this drug was known to depress total cholesterol biosynthesis in liver and total cholesterol pool's reduction in cell (Monson et al., 2007). The reduction of total cholesterol pool in cell caused increase in low-density lipoprotein (LDL) receptor expression in cell membrane. This increase promotes the elimination of pre-lipid protein like LDL, very low-density lipoprotein (VLDL), and intermediate-density

Received: May 14, 2020 / Revised: June 23, 2020 / Accepted: June 24, 2020

*Professor, ${ }^{* *}$ Graduate student.

${ }^{\dagger}$ Corresponding author: Seock Yeon Hwang. Department of Biomedical Laboratory Science, Daejeon University, 62 Daehak-ro, Dong-gu, Daejeon 34520, Korea.

Tel: +82-42-280-2802, Fax: +82-42-280-2904, e-mail: syhwang@dju.kr

(C) The Korean Society for Biomedical Laboratory Sciences. All rights reserved.

(c) This is an Open Access article distributed under the terms of the Creative Commons Attribution Non-Commercial License (http://creativecommons.org/licenses/by-nc/3.0/) which permits unrestricted non-commercial use, distribution, and reproduction in any medium, provided the original work is properly cited. 
lipoprotein (IDL) (Monson et al., 2007). Statin has a high advantage to reduce cholesterol concentrations in blood stream. However, it has side effects like liver damage and hyperplasia in kidney. Therefore, the needs of a new drug with natural substance are increasing these days (Monson et al., 2007). Recently, extracts from some natural products showed the effects in preventing and curing hyperlipidemia over decreasing several side effects in human body (Enkhmaa et al., 2005; Kang et al., 2007). For instance, studies of bioflavonoid of omega-3 fatty acid, benekol of vegetable steroid compounds, yacon, plum extract, evening primrose oil, citrus fruits, garlic extract, and citrus peel are underway.

Statin-like drugs used to treat hyperlipidemia showed various side effects like suppressing activation of 3-hydroxy3-methyl-glutaryl-coenzyme A (HMG-CoA) reductase in the biosynthetic pathway of T-Cholesterol (Leung et al., 2003). So many chemical drugs are having benefits that can lower cholesterol levels, but at the same time, are having serious side effects.

The mulberry is Morus alba L. in the family Moraceae. Major effective ingredients of the mulberry leaf are known flavonoid, amino acid, vitamins, and minerals etc. The root bark of mulberry may act as a potent hypocholesterolemic nutrient and powerful antioxidant via the inhibition of LDL atherogenic modifications and lipid peroxides formation in hypercholesterolemic rats (El-Beshbishy et al., 2006). The stem bark extracts of mulberry had the most potent inhibitory activity against lipid peroxidation (Khan et al., 2013). Therefore, it is expected to inhibit lipid peroxidation, metabolic diseases such as cholesterol, arteriosclerosis, and hyperlipidemia (Fujimoto and Nomura, 1985).

Yacon, Smallanthus sonchifolia (Poepp \& Endl.) H. Robinson is a species of perennial daisy belonging to family Compositae. The yacon is native to the Andes of South America (Novel, 1984). The names of yacon, which varies by country, is called 'liacon' in Peru and Bolivia, 'jiguima' in Venezuela and Argentina, 'arboloco' in Colombia, and 'yacon' in Japan (Asami et al., 1989). The tuberous root of yacon contains a large amount of fructo-oligosaccharide. It has been known that yacon prevents diabetes by reducing blood lipid and blood sugar for patient dietary (Chen et al., 2000). Also, tuberous root consists of $58.3 \%$ of the total soluble carbohydrates (Alvarez et al., 2008). The fructose and fructo-oligosaccharide in tuberous root is used as important functional component of natural sweetener, fructose has 1.5 2.0 times higher sweetness, lower intestinal absorption rate compared with sucrose, and fructo-oligosaccharide is a effective material in prevention of obesity, atherosclerosis and diabetes causing non-absorption and removing unuseful properties in body (Kim, 2005). It has been reported that yacon has the inhibitory effect on lipid hyperoxidation (Valentova et al., 2008).

The effect of mulberry leaf and yacon extracts on hyperlipidemia was tested in this study. The different ratios of mulberry leaf and yacon tuber extracts (MLYT) were mixed to induce a certain degree of synergistic effect. Evaluation of various major indicators to determine the effect on hyperlipidemia in preliminary test results showed that mulberry leaf and yacon definitely gave a positive effect on hyperlipidemia. Thus, we carried out this study for the indicators in the experiment of the hyperlipidemia using ethanol extract of MLYT based on the results from the preliminary study.

\section{MATERIALS AND METHODS}

\section{Preparation of sample and ethanol extraction}

Mulberry leaves and yacon were purchased from the Yakryeong Market, Seoul-Gyeongdong in Korea. The dried test substances (mulberry leaf $1 \mathrm{~kg}$, yacon $1 \mathrm{~kg}$ ) were added in stainless vessel (40 L) then $50 \%$ ethanol was added up $10 \mathrm{~L}$. After installation, the cooling sample tube was used for 8 hours at $85^{\circ} \mathrm{C}$. Obtained extract was filtered with Whatman filter paper No. 1 (Toyo Roshi Kaisha, Ltd., Japan) and $6 \mathrm{~L}$ of $70 \%$ ethanol was added to the remnant to extract the second sample. We used enough ethanol so the material is completely submerged and leaved the mixture in an ultralow temperature freezer for 24 hours. The process was repeated to get the third extract.

Each extract was mixed and concentrated by using rotary vacuum evaporator (N-1001S-W, Eyela, Tokyo, Japan). The concentrated solution was frozen and dried to obtain the final powder. So, the rate was $13 \%$ according to $130 \mathrm{~g}$ of freezerdried powder from $1 \mathrm{~kg}$ of mulberry leaf. In addition, the rate of yacon tuber was $9 \%$ in accordance with $90 \mathrm{~g}$. The 
Table 1. Composition of the experimental animals

\begin{tabular}{cccc}
\hline Group & Treatment & $\begin{array}{c}\text { Animals } \\
\text { (strain) }\end{array}$ & Number \\
\hline G1 & Normal & $\begin{array}{c}\text { Rats } \\
\text { (male, SD) }\end{array}$ & 10 \\
G2 & HFD & $\begin{array}{c}\text { Rats } \\
\text { (male, SD) }\end{array}$ & 10 \\
G3 & HFD + HCA & $\begin{array}{c}\text { Rats } \\
\text { (male, SD) }\end{array}$ & 10 \\
G4 & HFD + 1\% MLYT & $\begin{array}{c}\text { Rats } \\
\text { (male, SD) }\end{array}$ & 10 \\
G5 & HFD + 3\% MLYT & $\begin{array}{c}\text { Rats } \\
\text { (male, SD) }\end{array}$ & 10 \\
G6 & HFD + 5\% MLYT & $\begin{array}{c}\text { Rats } \\
\text { (male, SD) }\end{array}$ & 10 \\
\hline
\end{tabular}

HFD: High-fat diet, HCA: hydroxy citric acid, MLYT: mulberry leaf + yacon

powders mulberry leaf and yaconextracts with 50\% and 70\% ethanol were mixed with a ratio of $70 \%$ and $30 \%$ respectively for MLYT. The ratio of mulberry leaf and yacon extracts to induce a certain degree of synergistic effect were shown best results in preliminary test (data not shown).

\section{Experimental animals and diets}

Four-weeks old male Sprague-Dawley (SD) strain rats weighing approximately 100 150 g were purchased from DBL Ltd. (Um-sung, Chung-buk, Korea). It was acclimated to the feeding environment for one week and then healthy animals were used in the experiment. Animals were monitored in air-conditioned room at $23 \pm 2{ }^{\circ} \mathrm{C}$, relative humidity $(50 \pm 5 \%)$ and 12-hour light/dark cycle. Rats were divided into six groups (10 rats for each group) as following (Table 1). Normal diet group (G1), high fat diet group (G2), high fat diet with $0.5 \%$ hydroxycitric acid diet group (G3), high fat diet with 1\% MLYT group (G4), high fat diet with 3\% MLYT group (G5) and high fat diet with 5\% MLYT group (G6). Rats were induced to obesity with high fat diet during 4 weeks until their body weight were more than $30 \%$ of normal range and then divided to each group and fed test substance for 4 weeks.

The diets of normal and high-fat diet groups were provided with the composition of food as Table 2 (AIN 93-M). The experimental diets contain either a normal $(4.25 \mathrm{kcal} / \mathrm{g}$ of gross energy content) or high-fat $(5.20 \mathrm{kcal} / \mathrm{g}$ of gross energy content) and test groups of high-fat diet with $0.5 \%$ hydroxy citric acid in the positive control substance and concentration of $1 \%, 3 \%$, and $5 \%$ MLYT.

\section{Blood biochemical assay}

Autopsy was performed under ether anesthesia on animals fasted for 24 hours to carry out blood biochemical tests. Blood samples were collected from abdominal vein of all the groups of rats under ether anesthesia. Whole blood sample was collected in the serum separate tube (SST tube, BD vacutainer, USA) and left at room temperature for 30 minutes then centrifuged (504 RCF, $15 \mathrm{~min}$ ) to analyze the level of alanine transaminase (ALT), alkaline phosphatase (ALP), aspartate transaminase (AST), total cholesterol, triglycerides, phospholipid (PL) content with biochemical autoanalyzer (Hitach-747, Hitachi Medical, Co., LTD., Tokyo, Japan). Glucose concentration, lipid parameters including HDL-C and LDL-C were measured with the use of an ABX Pentra 400 analyzer (Horiba Medical, Montpellier, France).

\section{Measurement of lipid content in the liver and fecal}

Liver was dissected, blotted and snap frozen in liquid nitrogen. The fecal were collected and weighed last 4 days before the experiment. The samples were stored Ultra-Low Temperature Freezers $\left(-70^{\circ} \mathrm{C}\right)$. The lipid contents of liver tissue and fecal were measured with the method as described in Folch et al. (1957). The content of cholesterol was measured with the method as described in Zlatkis and Zak (1969). The contents of triglycerides were measure with the method as described in Biggs et al. (1975). The contents of bile acid in fecal was measured with the method as described in $\mathrm{Hu}$ et al. (2018).

\section{Measurement of HMG-CoA-reductase activity}

HMG-CoA-reductase activity was measured according to Kleinsek method (Kleinsek, 1980). $240 \mathrm{mM}$ potassium phosphate buffer $(300 \mathrm{mM} \mathrm{KCl}, 6 \mathrm{mM}$ EDTA, $15 \mathrm{mM}$ dithiothreitol, $\mathrm{pH}$ 7.4) was mixed with $2 \mathrm{mM}$ NADPH and $1 \mathrm{mM}$ HMG-CoA enzyme solution. The absorbance was detected at $37^{\circ} \mathrm{C}, 240 \mathrm{~nm}$. HMG-CoA-reductase activity was measured using molar extinction coefficient $6.22 \mathrm{mM}^{-1} \mathrm{~cm}^{-1}$. The unit of enzyme activity was deemed as the degraded 
Table 2. Composition $(\mathrm{g} / \mathrm{kg})$ of the experimental diets

\begin{tabular}{|c|c|c|c|c|c|c|}
\hline Constituent & G1 & G2 & G3 & G4 & G5 & G6 \\
\hline Casein & 200 & 200 & 200 & 200 & 200 & 200 \\
\hline Maize starch & 521 & 321 & 321 & 321 & 321 & 321 \\
\hline Sucrose & 100 & 100 & 100 & 100 & 100 & 100 \\
\hline Maize oil & 100 & 100 & 100 & 100 & 100 & 100 \\
\hline Lard & - & 200 & 200 & 200 & 200 & 200 \\
\hline Cellulose & 30 & 30 & 30 & 30 & 30 & 30 \\
\hline DL-methionine & 2 & 2 & 2 & 2 & 2 & 2 \\
\hline Mineral mix ${ }^{a}$ & 35 & 35 & 35 & 35 & 35 & 35 \\
\hline Vitamin mix ${ }^{\mathrm{b}}$ & 10 & 10 & 10 & 10 & 10 & 10 \\
\hline Choline bitartrate & 2 & 2 & 2 & 2 & 2 & 2 \\
\hline Gross energy content $(\mathrm{kcal} / \mathrm{g})$ & 4.25 & 5.20 & 5.20 & 5.20 & 5.20 & 5.20 \\
\hline
\end{tabular}

a) AIN mineral mixture $(\mathrm{g} / \mathrm{kg})$ : calcium phosphate dibasic 500 , sodium chloride 74 , potassium citrate 220 , potassium sulfate 52 , magnesium oxide 24 , manganous carbonate 3,5 , ferric citrate 6 , zinc carbonate 1,6 , cupric carbonate 0.3 , potassium iodate 0.01 , sodium selenate 0.01 , chrominium potassium sulfate 0.55

b) AIN vitamin mixture $(\mathrm{g} / \mathrm{kg})$ : thiamine $\mathrm{HCl} 0.6$, rivoflavin 0.6 , pyridoxine $\mathrm{HCl} \mathrm{0.7}$, niacin 3, calcium pantothenate 1.6, folic acid 0.2, biotin 0.02 , vitamin $\mathrm{B} 12(0.1 \%$ trituration in mannitol) 1 , dry vitamin A palmitate $(500,000 \mathrm{U} / \mathrm{g}) 0.8$ dry vitamin $\mathrm{E}$ acetate $(500 \mathrm{U} / \mathrm{g})$ 10 , vitamin $\mathrm{D}$, trituration $(400,000 \mathrm{U} / \mathrm{g}), 0.25$, manadione sodium bisulfate complex 0.15

amount of NADPH (pmole) produced per 1 minute from $1 \mathrm{mg}$ of protein.

\section{Legislation and animal treatments}

Investigators complied with the animal ethics law. All procedures were approved by the institutional ethics committee for the care and use of animals (Daejeon University, DJUARIB2012-05).

\section{Statistical analysis}

Statistical significance was analyzed by Duncan's multiple range test followed by one-way analysis of variance (ANOVA). and accepted if $P<0.05$. Statistical analysis was performed using the Statistical Package for Social Sciences 21.0 (SPSS) program. All numbers in data represent mean \pm standard deviation.

\section{RESULTS}

\section{Effects of MLYT on biochemical change in high-fat diet-fed rats}

Nonsignificant difference in total protein, albumin, ALP and ALT was observed among G1, G2, G3, and all the

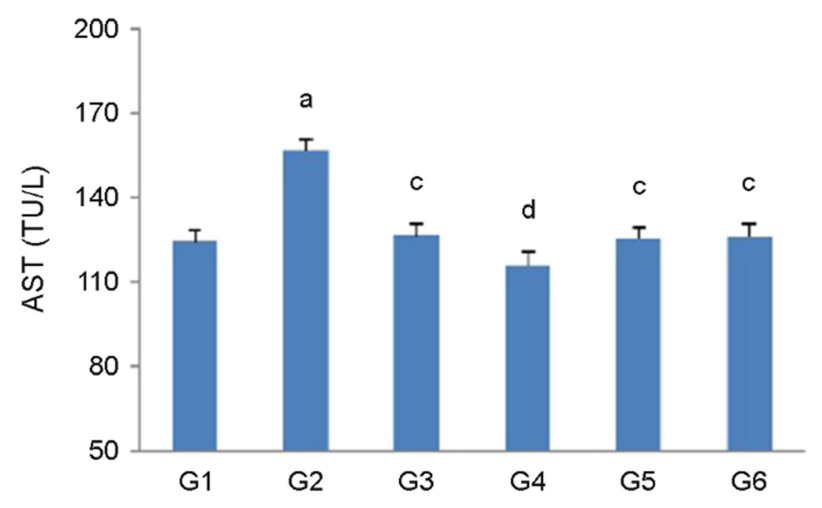

Fig. 1. Effect of MLYT (mulberry leaf + yacon) on aspartate transaminase (AST) activities in high-fat diet fed rats. AST, aspartate transaminase; ${ }^{a}$ Significantly different from normal $(P<0.05) .{ }^{\mathrm{c}, \mathrm{d}}$ Significantly different from high fat diet (HFD) alone $(P<0.05, P<0.01)$

treated groups (G4-G6) (Table 3). It was also no significant difference within groups $(P>0.05)$. However, AST as an indicator of liver function was significantly increased $26.2 \%$ in G2 compared to G1 $(P<0.05)$. But AST were significantly decreased in G3 and all the MLYT treated groups (G4-G6) compared to G2 (Fig. 1). 
Table 3. Effect of MLYT (mulberry leaf + yacon) on liver function in high-fat diet-fed rats

\begin{tabular}{cccccc}
\hline \hline Group & T. protein $(\mathrm{g} / \mathrm{dL})$ & Albumin $(\mathrm{mg} / \mathrm{dL})$ & ALP (IU/L) & ALT (IU/L) & AST (IU/L) \\
\hline G1 & $6.6 \pm 0.5$ & $3.4 \pm 0.3$ & $113.4 \pm 19.3$ & $38.2 \pm 6.7$ & $124.2 \pm 21.0$ \\
G2 & $5.7 \pm 0.4$ & $2.9 \pm 0.2$ & $126.2 \pm 20.3$ & $48.4 \pm 7.5$ & $156.7 \pm 20.4^{\mathrm{a}}$ \\
G3 & $6.1 \pm 0.5$ & $3.3 \pm 0.3$ & $119.5 \pm 16.7$ & $38.6 \pm 4.9$ & $126.3 \pm 21.3^{\mathrm{c}}$ \\
G4 & $6.2 \pm 0.6$ & $3.4 \pm 0.4$ & $101.3 \pm 21.5$ & $39.5 \pm 7.5$ & $115.6 \pm 26.1^{\mathrm{d}}$ \\
G5 & $6.5 \pm 0.6$ & $3.4 \pm 0.3$ & $112.4 \pm 15.9$ & $36.5 \pm 5.4$ & $125.4 \pm 19.2^{\mathrm{c}}$ \\
G6 & $6.5 \pm 0.6$ & $3.4 \pm 0.3$ & $116.4 \pm 18.7$ & $40.3 \pm 5.5$ & $126.1 \pm 23.9^{\mathrm{c}}$ \\
\hline
\end{tabular}

T. protein, total protein; ALP, alkaline phosphatase; ALT, alanine transaminase; AST, aspartate transaminase. ${ }^{\text {a Significantly different from }}$ normal $(P<0.05) .{ }^{\mathrm{c}, \mathrm{d}}$ Significantly different from HFD alone $(P<0.05, P<0.01)$

Table 4. Effect of MLYT (mulberry leaf + yacon) on serum lipids in high-fat diet-fed rats

\begin{tabular}{ccccccc}
\hline \hline Group & GLU (mg/dL) & T. Cho (mg/dL) & TG (mg/dL) & HDL-C (mg/dL) & LDL-C (mg/dL) & PL (mg/dL) \\
\hline G1 & $109.2 \pm 11.2$ & $75.6 \pm 4.9$ & $77.4 \pm 5.7$ & $53.4 \pm 4.8^{2}$ & $17.3 \pm 1.7$ & $11.7 \pm 1.1$ \\
G2 & $139.8 \pm 13.4^{\mathrm{a}}$ & $106.6 \pm 17.4^{\mathrm{a}}$ & $134.5 \pm 26.3^{\mathrm{b}}$ & $37.4 \pm 3.7^{\mathrm{b}}$ & $66.4 \pm 11.3^{\mathrm{b}}$ & $58.9 \pm 4.7^{\mathrm{b}}$ \\
G3 & $119.5 \pm 11.3^{\mathrm{c}}$ & $92.6 \pm 11.6$ & $96.4 \pm 7.8^{\mathrm{b}, \mathrm{d}}$ & $29.2 \pm 4.2^{\mathrm{b}, \mathrm{c}}$ & $35.3 \pm 2.7^{\mathrm{b}, \mathrm{d}}$ & $46.5 \pm 6.2^{\mathrm{b}}$ \\
G4 & $109.0 \pm 14.5^{\mathrm{c}}$ & $113.4 \pm 10.5^{\mathrm{a}}$ & $98.4 \pm 8.5$ & $44.5 \pm 7.4^{\mathrm{c}}$ & $44.5 \pm 5.1^{\mathrm{b}, \mathrm{c}}$ & $55.3 \pm 3.1^{\mathrm{b}}$ \\
G5 & $104.7 \pm 9.9^{\mathrm{c}}$ & $95.3 \pm 8.4^{\mathrm{c}}$ & $85.7 \pm 7.9^{\mathrm{c}}$ & $35.3 \pm 2.1^{\mathrm{b}}$ & $45.3 \pm 6.9^{\mathrm{b}, \mathrm{c}}$ & $58.6 \pm 6.3^{\mathrm{b}}$ \\
G6 & $117.2 \pm 11.4^{\mathrm{c}}$ & $89.3 \pm 5.8^{\mathrm{c}}$ & $85.3 \pm 7.4^{\mathrm{c}}$ & $38.6 \pm 4.8^{\mathrm{b}, \mathrm{c}}$ & $39.3 \pm 5.9^{\mathrm{b}, \mathrm{c}}$ & $59.4 \pm 6.4^{\mathrm{b}}$ \\
\hline
\end{tabular}

GLU, glucose; T-Cho, total cholesterol; TG, triglycerides; HDL, high-density lipoproteins; LDL, low-density lipoproteins; PL, phospholipids. a,b Significantly different from normal $(P<0.05, P<0.01)$. ${ }^{\mathrm{c}, \mathrm{d}}$ Significantly different from HFD alone $(P<0.05, P<0.01)$

\section{Effects of blood lipid metabolism improvement}

G2 was shown a $28.0 \%$ significantly increase in glucose compared to that of G1 $(P<0.05)$ (Table 4). But, glucose was significantly decreased G3, G4, G5, and G6 by $14.5 \%$, $22.0 \%, 25.1 \%$, and $16.2 \%$ compared to $\mathrm{G} 2$, respectively $(P$ $<0.05$ ). Total cholesterol was significantly increased $41.0 \%$ in $\mathrm{G} 2$ and $50.0 \%$ in $\mathrm{G} 4$ compared to $\mathrm{G} 1(P<0.05)$. But Total cholesterol was significantly decreased G3, G5, G6 compared to G2 $(P<0.05)$. Triglyceride was significantly increased by $73.7 \%$ in $\mathrm{G} 2$ compared to G1 $(P<0.01)$. But Triglyceride was significantly decreased G3, G5, and G6 by $28.3 \%$, and $36.2 \%, 36.5 \%$, compared to $\mathrm{G} 2$, respectively $(P<0.05)$. HDL of G2 and G3 was decreased compared to G1 by $30.0 \%$ and $45.3 \%(P<0.01)$. But Significantly increased to $3.2 \%$ in G6 was compared to G2 $(P<0.01)$. LDL of G2 was significantly increased 4 times $(283.8 \%)$ than G1. But Significantly decreased G3, G4, G5, and G6 by $46.8 \%$, $32.9 \%, 31.8 \%$, and $40.8 \%$ compared to $\mathrm{G} 2$, respectively $(P<0.05)$.

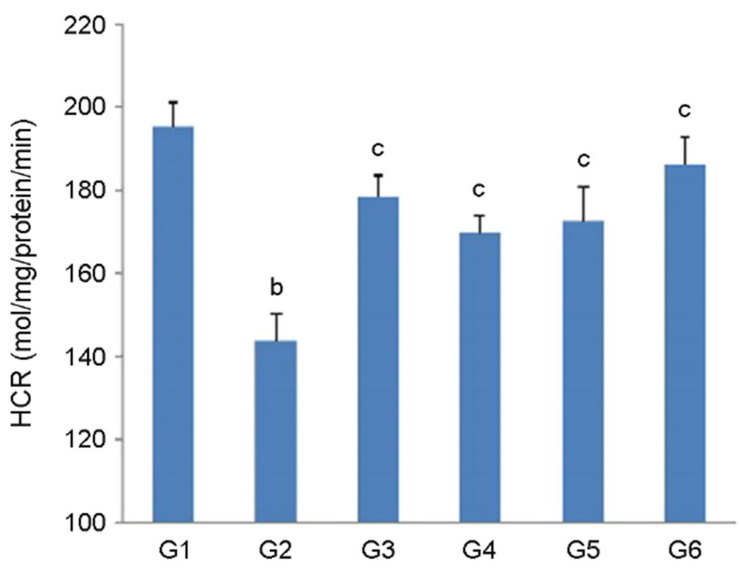

Fig. 2. Effect of MLYT (mulberry leaf + yacon) on HMG-CoA reductase (HCR) activity in high-fat diet-fed rats. ${ }^{\text {b Significantly }}$

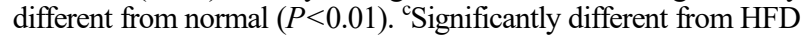
alone $(P<0.05)$.

\section{Effects of HMG-CoA reductase}

In case of HMG-CoA reductase, G2 was significantly decreased in $26.4 \%$ compared to G1 $(P<0.01)$ (Fig. 2). But there was increased $24.2 \%, 18.0 \%, 20.0 \%$, and $29.6 \%$ for $\mathrm{G} 3$, 
G4, G5, and G6 by compared to G2, respectively $(P<0.05)$.

\section{DISCUSSION}

MLYT treat groups decreased the levels of ALT and AST (Table 3). ALT and AST prevent liver expansion and lipid deposition. Additionally, they play roles in preventing and inhibiting weight gain from high fat diet, and recovering the reduced HDL. The serum lipid concentration decreased during physiological activity of mulberry flavonoid that consisted of quercetin, kaempferol and morin polyphenol compounds. In previous studies, experiments aimed at mulberry leaf in experimental animals by the injection of solvent extracts reduce the concentration of blood lipids and rat treated with a high cholesterol diet decreased serum cholesterol, reported to be consistent (Hong et al., 2005; Cho et al., 2005; Ryu et al., 2006). As a result, the proper combination of mulberry leaves and yacon tuber extract will have a synergistic effect on hyperlipidemia.

In animals, a high fat diet causes hyperlipidemia. Especillay, a high fat diet is metabolized through various metabolisms and accumulates in liver (Parry and Hodson, 2017). From this situation, hypercholesterolemia appears to increase the movement of cholesterol in liver. Furthermore, it was known that hyperlipidemia occurs due to increase of concentration on cholesterol and triglycerides in the blood plasma resulted from complication of diabetes mellitus (Hirano, 2018). It was reported that serum LDL decreased the activation of HMG-CoA reductase and HDL showed the increase of activation of HMG-CoA reductase (O'Meara et al., 1990; Edwards et al., 1984). In this study, it was statistically decreased in high fact diet group, but statistically increased in the treated group (Fig. 2). The inverse relationship between HMG-CoA reductase and LDL, appeared due to the reduction of LDL, and it was considered that cholesterol level of blood and liver tissue is decreased due to the negative feedback of HMG-CoA reductase (Choi and Lee, 1992; Hirano, 2018).

The content of glycose and lipids in the liver showed a significant depression effect in high-fat diet-fed groups compared with control group as well as in positive control group (HCA) and MLYT group, whereas in comparison to high-fat diet-fed group with MLYT group significantly increased in $3 \%$ MLYT $(P<0.05)$ (Table 4$)$. Such results indicate that the destruction of B-cell due to high-fat diet reduced the excretion of insulin, thereby decreasing the activation of glycogen syntheses in the liver, and increasing the activation of glycogen phosphorylase, an enzyme which breaks down glycogen (Huang et al., 2019). This would be a main reason in reducing the content of glycogen in the liver. That blood glucose contents were significantly decreased in 3\% MLYT treated group would result from increasing in the content of glycogen in the liver.

These fatty changes (steatosis), common lesions in the liver, are assumed to be the vacuoles of fat in the cytoplasm. The fat in the cytoplasm of liver causes damages to organelles, metabolic disorders, the deficiency of lipotrophic factor and ultimately excessive accumulation of fat in the liver. The free fatty acid produced by dietary fat or adipose tissue is used as the source of energy, and triglycerides and phospholipids was synthesized from a part of the free fatty acid by esterification in the endoplasmic reticulum. In addition, triglycerides and apoprotein B combine to produce the lipoprotein in the endoplasmic reticulum. A number of cells except the liver and intestines are not able to effectively use fatty acid, but use fats of proteolipid as the source of energy. In this study, we observed the inhibitory effect of MLYT on hyperlipidemia. These effect of MLYT seems to result in inhibiting the oxidative reaction in liver from the high-fat diet-fed rats. Laboratory and animal studies of HCA have produced results that indicate a potential for modulation of lipid metabolism (Shara et al., 2003). However, a clinical study has demonstrated that HCA has no effect in terms of weight loss or reduction of fat mass (Heymsfield et al., 1998). A few clinical toxicity reports on weight-loss diet supplements of which some were combinations that included Garcinia/HCA as an active ingredient showed potential toxicity towards spermatogenesis (Chuah et al., 2012). That the nature of the HCA-containing source is important was made clear years ago in a critical analysis of another study that purported to demonstrate toxicity, in that particular case, testicular toxicity, at high dosages (Clouatre and Preuss, 2013). For hyperlipidemia, the 3 5\% MYE treatment group is generally similar to or more effective than the HCA treat- 
ment group.

In summary, it is concluded that MLYT have significant effects on anti-hyperlipidemic effects against high fat diet. Thereby, it seems that MLYT prevent fatty liver and hyperlipidemia caused by high-fat diet. Thus, the mulberry leaves and yacon extracts can play a role in preventing fat accumulation, which can be the basis of the development of antihyperlipidemia agents of natural materials.

\section{ACKNOWLEDGEMENT}

None.

\section{CONFLICTS OF INTEREST}

The researcher claims no conflicts of interest.

\section{REFERENCES}

Alvarez FPP, Jurado TB, Calixto CM, Incio VN, Silva AJ. Prebiotic inulin/oligofructose in yacon root (Smallanthus sonchifolius), phytochemistry and standardization as basis for clinical and preclinical research. Rev Gastroenterol Peru. 2008. 28: 22-27.

Asami T, Kubota M, Minamisawa K, Tsukihashi T. Chemical composition of yacon, a new root crop from Andean highland. Jpn J Soli Sci Plant Nutr. 1989. 60: 122-126.

Biggs HG, Erikson TM, Moorehead WR. A manual colorimetric assay of triglyceride in serum. Clin Chem. 1975. 21: 437-441.

Carroll MD, Fryar CD, Nguyen DT. Total and High-density Lipoprotein Cholesterol in Adults: United States, 2015-2016. NCHS Data Brief. 2017. 290: 1-8.

Chen HL, Lu YH, Lin JJ, Ko LY. Effects of fructooligosaccharide on bowel function and indicators of nutritional status in constipated elderly men. Nutr Res. 2000. 20: 1725-1733.

Cho JH, Lee NJ, Hong SH, Kim DK, Shin S, Park JH, Kang JK, Kim YB, Hwang SY. Effect of HGD-201 on obesity induced by high fat diet in Zucker rats. Lab Anim Res. 2005. 21: 158 $-163$.

Choi YS, Lee SY. Serum cholesterol and 3-hydroxy-3-methylglutaryl coenzyme A reductase. J Korean Soc Food Nutr. 1992. 21: 580-593.

Chuah L, Yeap SK, Ho WY, Beh BK, Alitheen NB. In vitro and in vivo toxicity of garciniaor hydroxycitric acid: A review. Evid Based Complement Alternat Med. 2012. 2012: 197920.

Clouatre DL, Preuss HG. Hydroxycitric acid does not promote inflammation or liver toxicity. World J Gastroenterol. 2013. 19: $8160-8162$

Davis JT, Delfino SF, Feinberg CE, Johnson MF, Nappi VL, Olinger JT, Schwab AP, Swanson HI. Current and emerging uses of statins in clinical therapeutics: a review. Lipid Insights. 2016. 9: $13-29$

Edwards PA, Lan SF, Fogelman AM. High density lipoproteins and lecthin dispersions increase the activity of 3-hydroxy-3methlyglutaryl coenzyme A reductase by increasing the rate of synthesis and decreasing the rate of degradation of the enzyme. J Biol Chem. 1984. 259: 8190-8194.

El-Beshbishy HA, Singab AN, Sinkkonen J, Pihlaja K. Hypolipidemic and antioxidant effects of Morus alba L. (Egyptian mulberry) root bark fractions supplementation in cholesterolfed rats. Life Sci. 2006. 78: 2724-2733.

Enkhmaa B, Shiwaku K, Katsube T, Kitajima K, Anuurad E, Yamasaki M, Yamane Y. Mulberry (Morus alba L.) leaves and their major flavonol quercetin 3-(6-malonylglucoside) attenuate atherosclerotic lesion development in LDL receptordeficient mice. Nutr. 2005. 135: 729-734.

Folch J, Lees M, Stanley GHS. A simple method for the isolation and purification of total lipids from animal tissues. J Biol Chem. 1957. 226: 497-509.

Fujimoto T, Nomura T. Components of root bark of Cudrania tricuspidata 3. Isolation and structure studies on the flavonoids. Planta Med. 1985. 51: 190-196.

Heymsfield SB, Allison DB, Vasselli JR, Pietrobelli A, Greenfield D, Nunez C. Garcinia cambogia (hydroxycitric acid) as a potential antiobesity agent: a randomized controlled trial. JAMA. 1998. 280: 1596-1600.

Hirano T. Pathophysiology of diabetic dyslipidemia. J Atheroscler Thromb. 2018. 25: 771-782.

Hong SH, Chai HY, Kim TM, Lee NJ, Kim DK, Cho JH, Park JH, Kim YB, Kang JK, Hwang SY. Therapeutic effects of mulberry root-bark (Mori radicis cortex) ethanol extract on atherosclerosis in hypercholesterolemic rabbits. Lab Anim Sci. 2005. 21: 273-279.

Hu PL, Yuan YH, Yue TL, Guo CF. Bile acid patterns in commercially available oxgall powders used for the evaluation of the bile tolerance ability of potential probiotics. PLoS One. 2018. 13: e0192964.

Huang S, Tang N, Zhao H, Tang CL. Effect of electrical stimulation combined with diet therapy on insulin resistance via mTOR signaling. Molecular Medicine Reports. 2019. 20: 
$5152-5162$

Kang SU, Wi TS, Yun DH. The effect of the Raphanus sativus L. acupuncture in high lipid induced obesity depend on body mass index. J Kor Acupuncture. 2007. 24: 113-125.

Khan MA, Rahman AA, Islam S, Khandokhar P, Parvin S, Islam MB, Hossain M, Rashid M, Sadik G, Nasrin S, Mollah MN, Alam AH. A comparative study on the antioxidant activity of methanolic extracts from different parts of Morus alba L. (Moraceae). BMC Res Notes. 2013. 19: 6-24.

Kim YS. Antimicrobial activity of yacon K-23 and manufacture of functional yacon jam. Korean J Food Sci. 2005. 37: 1035 -1038 .

Kleinsek DA, Jabalquinto AM, Porter JW. In vivo and in vitro mechanisms regulating rat liver beta-hydroxy-beta-methylglutaryl coenzyme A reductase activity. J Biol Chem. 1980. 255: 3918-3923.

Leung WYS, Thomas GN, Ghan JCN, Tominson B. Weight management and current option in pharmacotherapy: orlistat and sibutramine. Clinical Therapeutics. 2003. 25: 58-80.

Monson Js, Jonsson P, Koltowska-Haggstrom M, Kourides I. Growth hormone $(\mathrm{GH})$ replacement decreases serum total and LDL in hypopituitary patients on maintenance HMGCoA reductase inhibitor (Statin) therapy. Clin Endocrinol. 2007. 67: 623-628.

Novel V. The lost crops of the Incas. Ceres. 1984. 17: 37-40.

O'Meara NMG, Devery RAM, Owens D, Collins PB, Johnson AH, Tomkin GH. Cholesterol metabolism in alloxan induced dia- betic rabbits. Diabetes. 1990. 39: 626-633.

Parry SA, Hodson L. Influence of dietary macronutrients on liver fat accumulation and metabolism. J Investig Med. 2017. 65: 1102-1115.

Ryu JM, Cho JH, Chai HY, Kim TM, Park JH, Kim YB, Hwang SY. Improvement effect of mulberry root-bark (Mori radicis cortex) water extract on atherosclerosis in hypercholesterolemic rabbits. Lab Anim Res. 2006. 22: 83-89.

Shara M, Ohia SE, Yasmin T, Zardetto-Smith A, Kincaid A, Bagchi M, Chatterjee A, Bagchi D, Srohs SJ. Dose- and timedependent effects of a novel-hydroxycitric acid extract on body weight, hepatic and testicular lipid peroxidation, DNA fragmentation and histopathological data over a period of 90 days. Mol Cell Biochem. 2003. 254: 339-346.

Valentova K, Stejskal D, Bartek J, Dvoracva S, Kren V, Ulrichova J. Maca (Lepidium meyenii) and yacon (Smallanthus sonchifolius) in combination with silymarin as food supplements: in vivo safety assessment. Food Chem Toxicol. 2008. 46: 1006-1013.

Zlatkis A, Zak B. Study of a new cholesterol reagent. Anal Biochem. 1969. 29: 143-146.

https://doi.org/10.15616/BSL.2020.26.2.101

Cite this article as: Lim Y, Oh JH, Park UK, Huh MK, Hwang SY. Protective Effect of Mulberry Leaf and Yacon Extract Induced Hyperlipidemia in Obese Rats. Biomedical Science Letters. 2020. 26: 101-108. 